\title{
Notas sobre Teoria e Práxis
}

\section{Elaine Conte*}

Resumo: O trabalho busca discutir o poder de determinação que a teoria e a prática possuem na educação contemporânea, diante da necessidade inquestionável de atualizar a teoria e de reconhecer as imensas exigências para uma ação crítica frente às questões tecnológicas, salientando a necessidade do diálogo e do aprender na atualidade. Percebemos a larga influência da epistemologia da prática nas pesquisas atuais sobre formação de professores, bem como nas políticas oficiais, baseadas em conhecimentos científicos de racionalidade procedimental e no mundo da experiência pedagógica, cujo diagnóstico revela o seu empobrecimento e desqualificação no âmbito da vida social. Para além de uma relação entre teoria e prática, na qual uma determina o que deve ser utilmente aceitável da outra, apostamos como saídas as teorias para a expressão da ação livre, criativa e autônoma, reafirmando a necessidade de abertura à mudança como retomada da valorização da prática social.

Palavras-chave: Teoria. Prática. Práxis pedagógica.

\section{Notes on theory and praxis}

Abstract: The paper discusses the power determination that theory and practice have in contemporary education, given the unquestionable necessity to update the theory and recognize the huge demands for critical action on the technology issues, emphasizing the need for dialogue and learning in today. We realize the wide influence of epistemology practice in current research on teacher education, as well as in official policies, based on scientific knowledge of procedural rationality and on the world of pedagogical experience,

* Doutora em Educação pela Universidade Federal do Rio Grande do Sul. Professora e pesquisadora do Centro Universitário La Salle (UNILASALLE). E-mail: elaineconte.poa@gmail.com 
whose diagnosis reveals its impoverishment and disqualification in social life. In addition to a relation between theory and practice, in which a determines what should properly be acceptable in another, bet theories as outputs for the expression of free, creative and autonomous action, reaffirming the need for openness to change as resumption of valuing social practice.

Keywords: Theory. Practice. Pedagogical Práxis.

\section{Notas acerca de la teoría y la práxis}

Resumen: El trabajo discute el poder de determinación que la teoría y la práctica tienen en la educación contemporánea, dada la indudable necesidad de actualizar la teoría y reconocer las inmensas demandas de una acción crítica frente a los problemas tecnológicos, subrayando la necesidad de diálogo y de aprendizaje en la actualidad. Nos damos cuenta de la gran influencia de la epistemologia de la práctica en la investigación actual sobre la formación del profesorado, así como las políticas oficiales basadas en el conocimiento científico de la racionalidad procedimental y en el mundo de la experiencia pedagógica, cuyo diagnóstico revela su empobrecimiento y la descalificación en la vida social. Además de una relación entre la teoría y la práctica, en la cual una determina lo que debe ser adecuadamente aceptable la otra, apostamos como salidas teorías del diálogo para la expresión de la acción libre, creativa y autónoma, lo que reafirma la necesidad de una apertura al cambio como la reanudación de la apreciación la práctica social.

Palabras clave: Teoría. Práctica. Praxis pedagógica.

\section{Os limites da ação pedagógica}

A preocupação inicial deste trabalho está no fato de que os limites das dicotomizações no mundo educacional causam a instrumentalização 
da teoria ${ }^{1}$ e a sua subserviência à prática, ${ }^{2}$ provocando a carência na mediação tecnológica (enquanto prática interativa), a retomada do sempre igual, a mediocridade do ensino (associado ao fetichismo) e a banalização das culturas. Tal posição seria originada da separação artificial teoria prática decorrente da epistemologia cartesiana. Há aqui a necessidade de direcionar o tema para uma heurística da ação pedagógica, que não se resolve simplesmente apelando para a instância da prática e abolindo a instância teórica, mas requer uma análise em favor do caráter interativo do processo formativo. Na verdade, a ação educativa é ou deveria ser marcada pela abertura ao diálogo e à mudança, pela descolonização dos saberes e reconstrução de novas propostas integradoras necessárias à ação crítica e emancipatória. O ensaio desenvolve a ampliação do diálogo teoria-prática na formação de professores sob o horizonte hermenêutico das discussões filosóficas de Adorno, Freire e Habermas, que fornecem largas contribuições para a educação na constituição das sociedades pluralistas em que vivemos. Mas como problematizar o papel da teoria e da prática na formação de professores? Como manter o exercício dialético

1 Teoria significa o conhecimento especulativo considerado com independência de toda aplicação. Desde a ontologia de Parmênides estava ligada à contemplação do universo, deveria manter-se afastada de toda incerteza e mutabilidade. A etimologia da palavra remonta a Theorós, que era a pessoa enviada a consultar um oráculo, e posteriormente, o enviado pelas cidades gregas como observador dos jogos. A palavra foi sendo transformada em termos filosóficos e adquirindo o conceito de visão, e daí transformou-se no conceito latino de teoria. A herança negativa desse conceito trouxe a característica de aplicar seus métodos teóricos à vida social sem refletir sobre os interesses que guiam o conhecimento. Para Habermas (1982), as ciências humanas e sociais absorveram disso a ilusão da teoria pura e da ciência "objetiva", separada dos interesses do mundo e até com certo desprezo por eles.

2 A prática remonta a palavra grega práxis que pode ser traduzida habitualmente por fazer humano, atividade, realização de fins, execução de propósitos, obtenção de êxitos e resultados de acordo com uma realidade imediata. No mundo tecnológico atual o fazer se interconecta com a técnica que é validada por seu êxito, mas que carrega em seu sentido original a relação com a arte, com o desvelar e o desocultar. O problema está na fetichização da técnica que se une aos planos de uma teoria objetiva e de um desconhecimento dos interesses que a governam (ADORNO, 1995). 
da ação educativa nos limites da razão técnica? Que racionalidade pode fazer frente ao tipo procedimental presente nos processos formativos de professores, se a prática e a teoria estabelecem uma relação hostil baseada na fixidez e uniformização? Nesse contexto, desmistificar a teoria e a prática na educação há de significar também o reconhecimento de diferentes abordagens teóricas que provocam a sensibilização para o conhecimento da vida concreta, uma vez que imperam as tecnologias eminentemente práticas, com forte conexão e socialização dos conhecimentos, que requerem a constante vitalidade autocrítica. Contra o enclausuramento da teoria em face à práxis e vice-versa, repensamos a dimensão tensional presente em toda a relação com a diversidade e alteridade própria do agir pedagógico, problematizando as noções de dialogicidade, criticidade, inacabamento relacional, instrumentalismo e verticalidade do ensino, que perpassam as compreensões teórico-práticas e político-pedagógicas.

O confronto entre os limites e impasses teóricos na prática cotidiana, desenvolvido pela educação brasileira, inspira novas reflexões para o rompimento das amarras dualistas, recriando a dialeticidade e a radicalidade das correlações na práxis $^{3}$, vinculadas à inquietante abertura para a comunicação descentrada do mundo. Esse propósito pode ser alcançado, com o auxílio de Adorno, Freire e Habermas $^{5}$, na medida em

3 Gramsci (1991) diz que Marx, o fundador da filosofia da práxis, teria não apenas rompido com o antigo, mas teria sido também um intérprete moderno de fenômenos sociais que trouxeram em si, os germes de sua própria transformação. Para Marx, a revolução seria realmente a verdadeira práxis, a prática social da humanidade (trabalho) incorporada de teoria. Consideramos que a práxis (ou prática) é contraditória porque contêm em si, ao mesmo tempo, a autoatividade, a espontaneidade e a autoalienação.

4 Paulo Freire (1921 - 1997) considerava fundamental a abertura para a ação criadora e transformadora de suas próprias ideias, trazendo implicações nos estudos da comunicação humana midiatizada pelo mundo.

5 Os fios condutores nos trabalhos de Jürgen Habermas (1929) estão integrados e procuram elucidar a relação entre a teoria e a práxis vital, a partir, primeiramente, da crítica ao positivismo, em seguida, numa perspectiva político-cultural, quando desenvolve a crítica ao Estado e à sociedade, e na última fase, numa teoria da competência comunicativa, que caracteriza a teoria do agir comunicativo. 
que a formação educativa passa a ser associada à problematização da ação humana no mundo. Aqui há uma presença conflituosa de opostos, sem dúvida, mas que se encontram e se complementam, pois o que está em jogo é uma luta por reconhecimento mútuo de interdependência entre teoria e prática, que só pode ser apreendida nos processos de reflexão contínua sobre o tema.

Na sociedade moderna, o apelo à aplicação imediata da teoria sufoca o potencial crítico do pensamento e submete a própria teoria à impaciência da prática. Para Adorno (1992), reconhecer nas teorias os horizontes necessários que nos ajudem a pensar o concreto não significa uma adesão imediata e dogmática a qualquer uma delas. A despeito de seu caráter prático, o pensamento dialético é aquele que recusa, intransigente, qualquer forma de reificação, inclusive de si mesmo. Adorno faz afirmações polêmicas quanto à relação teoria e prática quando defende não apenas a autonomia da teoria em relação à prática, como também o caráter prático da própria teoria. É nesse sentido que manifesta a ideia de que "pensar é um agir, teoria é uma forma de práxis" (ADORNO, 1992, p. 204), que se apresenta como um momento ativo e criador do sujeito em face da práxis vital alienada. Para o autor, teoria e prática não são de imediato as mesmas, nem absolutamente distintas. A prática é fonte da teoria, mas esta não pode ser arrancada do conjunto do processo social. Segundo Freire (1996), a ação só é humana quando, mais que um puro fazer, é um fazer que também não se dicotomiza da reflexão. Contudo, o autor reconhece que a práxis educativa não é um ato solitário, mas está diretamente ligada à relação com o outro. Nessa perspectiva, a própria teoria adquire força de ação transformadora, recebendo um novo significado integralmente relacionado à prática, sendo, portanto, necessário o reconhecimento da prática para além das justificações heterogêneas e fragmentadas da vida. O desafio posto por Freire é o de elaborar um projeto formativo e educativo que auxilie na desdogmatização da prática e na desintrumentalização da teoria. Já Habermas (1982) converte o conceito de razão prática em racionalidade comunicativa em seus estudos acerca da 
teoria e práxis. O autor desenvolve uma teoria do conhecimento (a partir da insatisfação com o encaminhamento da Teoria Crítica), utilizando a linguagem como categoria de excelência da racionalidade, capaz de reconstruir a unidade perdida entre ação e reflexão, teoria e práxis. No que segue, recorremos a uma ampliação das linguagens empregadas nesse dilema teoria-prática, para compreender as suas dimensões pedagógicas, éticas e políticas na educação.

\section{Tendências teórico-práticas e político-pedagógicas}

Em tempos de crise em todas as instâncias sociais no País, notadamente com a consolidação do desprezo em relação à vida e ao cultivo intelectual, nada mais imperativo do que continuar teorizando contra a prática ortodoxa, buscando a radicalidade e a profundidade teórica comprometida com a criticidade e não apenas com a prática meramente afirmativa. A ação humana é sensível e necessária para ler e interpretar o mundo, para desenvolver o aprendizado de conceitos que abrem espaços para a pergunta e a crítica como possibilidade de um pensamento de resistência. Pensando o mundo da vida a partir da possibilidade de unificação entre teoria e prática enquanto devir histórico, chegamos ao ponto de vista de Gramsci (1991), que partilha uma concepção de mundo revolucionária, questionadora dos perversos reducionismos da duplicidade. A tensão permanente entre teoria e prática como uma verdadeira prática revolucionária depende de uma ação dialética de abertura para com o outro, uma vez que o caráter impotente assumido pelo dialógico crítico e questionador tem como consequência a indigência da prática. Sua crítica dirige-se, sobretudo, à imposição dos critérios da racionalidade instrumental que torna as intervenções educativas homogêneas, impessoais, descontextualizadas e distantes do mundo vivido, sem pretensões transformadoras. Talvez a contingência de uma prática mediadora da relação de contradição e o exercício constante da crítica poderá qualificar as práticas pedagó- 
gicas, uma vez que a educação passa a compreender as necessidades próprias dos diferentes mundos constituídos intersubjetivamente. A partir desse ponto, a formação pode cumprir funções político-sociais, auxiliando na superação das dificuldades concretas dos processos educativos e colaborando na formação humana.

Com base na tradição justificada em autores como Gramsci (1991) e Freire (1996), podemos dizer que a teoria e a prática são consideradas como uma unidade, onde a teoria nutre a prática social, representando a força transformadora. Por essa razão, a teoria é sempre histórica e nasce da prática, por isso compreender uma prática significa conhecer seus elementos teóricos. Na verdade, tudo é prática e está imerso em relações de poder, conhecimento e interesse, que se implicam mutuamente. As condições históricas dos sujeitos e dos contextos influenciam o desenvolvimento das práticas educativas, como observa Minasi (2008, p. 83), "a teoria, como reflexo da prática, precisa ser entendida como um conjunto de conceitos sistematicamente organizado que reflete a realidade dos fenômenos materiais sobre a qual foi construído e que serve para descrever, interpretar, explicar e compreender o mundo". A relação entre o teórico e o prático está ligada à prática concreta, à ideia de transformação dos meios de produção, visando desenvolver uma teoria crítica da prática, como práxis libertadora, tendo em vista o desenvolvimento de uma sociedade mais justa e democrática. Como dizia Paulo Freire (1996), nada mais prático que uma boa teoria, por essência relacionada à prática, pois o mundo não é acessível independentemente dos sujeitos e dos processos de poder curriculares, profissionais e institucionais. Portanto, teorizar é iluminar a ação, é decifrá-la, é reaprender o movimento do real para ajudar a transformá-la.

Nesse ponto da argumentação, apostamos no entendimento dialógico como possibilidade de coordenação da teoria e da prática na formação de professores, como um caminho para o processo de revisão das investigações na área, que exige de todos um aprendizado comunicativo 
das múltiplas interpretações da práxis educativa ${ }^{6}$ (HABERMAS, 1987; FREIRE, 2001). Cabe ainda registrar que as argumentações têm uma espécie de função reparadora que ultrapassa o nível explicativo e descritivo das realidades práticas, pois nossas visões de mundo, apreciações e crenças estão enraizadas em mundos construídos por nós em interação com os outros. A ação educativa está diretamente ligada à práxis, sendo essa, numa perspectiva freireana, entendida como a reflexão e ação dos homens sobre o mundo para transformá-lo. Nesse enfoque a teoria penetra na práxis vital e impregna a vida de uma formação orientada para a ação. Afinal de contas, de nada adianta o discurso competente se a ação pedagógica é impermeável às mudanças. Assim, a reflexão crítica sobre a prática se torna uma exigência da relação teoria-prática sem a qual a teoria pode virar um monólogo da formação teórica e a prática, ativismo.

Aqui a relação entre a teoria e a prática surge como uma questão central para poder refletir sobre as aporias entre educação e política. $\mathrm{O}$ velho dilema entre teoria e prática torna-se atualmente um dos principais eixos articuladores da formação de professores nos cursos de Pedagogia do Brasil (BRASIL, 2001). A articulação entre teoria e prática proposta na formação de professores pela legislação procura equacionar diversos aspectos, tanto aqueles relativos aos projetos pedagógicos quanto os curriculares e o problema dos estágios, mas acaba privilegiando a prática explicativa em detrimento da teoria. Nota-se que há uma dificuldade das políticas de formação de professores em aliar teoria e prática. Isso porque, com a aplicação indiscriminada das teorias das competências no campo da formação de professores não há uma transição da visão normativa para uma visão prática, mas sim a passagem para uma teoria explicativa. Tal procedimento apenas reforça o modelo do professor transmissor e

$6 \quad$ A práxis educativa transcende os limites dos conteúdos conceituais disciplinares e do silêncio intramuros, porque torna os sujeitos partícipes da aventura histórica do processo de construção do mundo e da humanização do ser humano, enfocando a realidade concreta, os dramas sociais e a ação necessária a sua transformação. 
explicador, evidenciado com a imposição do logos teorizador, que tornou o corpo escravo da alma, as emoções da razão, a pluralidade da unidade, o diferente do homogêneo, a prática escrava da teoria, a arte separada da técnica.

Nesse sentido, a formação do professor não pode ficar refém de uma pretensa teoria ou da prática alienada, como refere Pimenta (2006, p. 43), "o professor pode produzir conhecimento a partir da prática, desde que na investigação reflita intencionalmente sobre ela, problematizando os resultados obtidos com o suporte da teoria. E, portanto, como pesquisador de sua própria prática". A educação pode tirar conclusões importantes deste contexto, necessitando um envolvimento tanto de caráter teórico quanto prático, dado que o reconhecimento dialógico promove igualmente a articulação entre estes elementos. Nesse sentido, Tardif (2010) concebe a prática como uma dimensão formativa do trabalho docente, propondo a compreensão da natureza dos saberes utilizados e o papel que desempenham na profissão, na qual evoluem e se transformam. A ideia é entender os saberes docentes como saberes próprios da profissão, impregnados de questionamentos e anseios, que englobam "os conhecimentos, as competências, as habilidades (ou aptidões) e as atitudes, isso é, aquilo que muitas vezes foi chamado de saber, saber-fazer, e saber-ser" (TARDIF, 2010, p. 257). Essa abordagem permite a apreensão, interpretação e descrição dos processos de decisão tomados pelos professores diante de dilemas sobre os conhecimentos (inclusive os tecnológicos) e dificuldades que encontram em seu contexto de atuação. Para Tardif (2010, p. 256), “a finalidade de uma epistemologia da prática profissional é revelar esses saberes, compreender como são integrados concretamente nas tarefas dos profissionais", pois eles são produzidos, incorporados e transformados em função dos limites inerentes à experiência da ação cotidiana dos professores. Nesse caso, os professores tornam-se produtores de conhecimentos próprios, a partir de esquemas conceituais abertos à interação comunicativa, do que dependem as atividades de ensino. 
Nos últimos tempos, o debate sobre a formação de professores no Brasil vem sendo revigorado através de uma série de trabalhos, entre os quais citamos Macedo (2010) e Minasi (2008), que apostam na qualificação das práticas formativas por meio de processos coletivos e compartilhados, seja em comunidades de aprendizagem, em redes e espaços de comunicação, na prática de ensino, na formação do professor reflexivo, na compreensão do plano político e curricular como ponto principal da configuração socioeducativa, na formação como condição e possibilidade de aprendizagem e na pesquisa como articulação da teoria e prática. Nessas investigações, balizadas em experiências particulares, observa-se ainda a carência em encontrar, no discurso intersubjetivo, a possibilidade de realizar acordos sobre a viabilidade das práticas com os objetivos da formação, bem como a resolução das contradições que fragmentam a formação de professores. As percepções expressam as teorias enquanto modos de ler, interpretar a realidade e agir no mundo. Nesse aspecto, a abordagem da complexidade de Morin (2008, p. 335) expressa que "uma teoria não é o conhecimento; ela permite o conhecimento. Uma teoria não é uma chegada; é a possibilidade de uma partida. Uma teoria não é uma solução; é a possibilidade de tratar um problema". Nessa perspectiva, a teoria realiza-se na atividade pensante do sujeito, na sua capacidade de intervenção e criação, estabelecendo uma relação entre método ${ }^{7}$ e teoria, ambos indispensáveis ao pensamento complexo. Segundo Morin, a teoria é um meio-fim inscrito em permanente recorrência, expressandose no método como estratégia da complexidade e ação reorganizadora da teoria. Para Morin (2007, p. 80), "o desenvolvimento de um conhecimento objetivo no mundo deve avançar junto com um conhecimento subjetivo do outro", pois a compreensão só pode ocorrer na processualidade da vida de

Há uma controvérsia a respeito do método no mundo acadêmico. Alguns professores, como Dermeval Saviani, acreditam que o método deve ocupar posição de destaque nos trabalhos acadêmicos, enquanto outros, como Moacir Gadotti, pensam que o método é o próprio processo de pesquisa exposto ao longo do texto, e que, portanto, não necessita receber uma ênfase excessiva. Acreditamos, com Hegel, que o conteúdo é que determina o método. 
forma intersubjetiva. No presente, os preceitos de uma educação dialógica inspirada nas teorias de Adorno, Freire e Habermas servem de inspiração para melhor compreender a relação teoria-prática na formação do professor e promover uma articulação dialética dessas instâncias no reconhecimento social, sem abandonar a preocupação com os conteúdos. Esses pensadores não pretendem simplesmente afirmar o primado da dimensão prática em detrimento da teórica, mas, antes, colocar em discussão a oposição artificial entre os dois âmbitos inseparáveis da formação, incorporando também as tendências transformadoras, críticas e comunicativas próprias do agir humano.

\section{A aversão à teoria constitui a fragilidade da práxis}

A teoria na modernidade é prática, é ação, pois se ela não tiver este caráter de utilidade ou de transformação, não pode ser considerada afinada aos princípios da modernidade. Como alerta Adorno (1992), nessa percepção corremos o risco de mistificar a prática alienada, que se pretende superior e autossuficiente, atribuindo-lhe um caráter sagrado, pois num mundo administrado a reflexão é tornada secundária e o impulso à adaptação apressada faz uma transposição direta à práxis, anulando o papel mediador do sujeito. Desse modo, Adorno (1992) mostra o grande valor que possui a teoria, sobretudo a práxis crítica, transformadora, atividade livre, frente à práxis alienada, fragmentada e de um fazer utilitarista tradicional, com objetivos imediatos, sobre os quais não há questionamentos. A necessidade moderna de dar uma resposta imediata ao que fazer impede o pensamento crítico, o que demonstra a grande aversão pedagógica à teoria, ou seja, gera-se uma despotenciação da prática resultante de uma atividade impermeabilizada contra a teoria. Assim, a radical separação teoria e prática nos convida a perceber que é no ato de crítica reflexiva e resistência ao pensamento uniformizador, que lançamos o olhar para o diferente, o desviante, o outro que ainda não foi homogeneizado e capturado pelo esquema conceitual geral. 
Adorno (1992) diverge da tese da unidade teoria-prática, a qual chama de dogma, porque acredita que a relação entre ambas é de contradição, de descontinuidade, vinculando-se a uma certa relação entre sujeito e objeto. A origem da crise da relação entre teoria e prática, para Adorno (1992), está no cerne da sociedade capitalista, que leva à coisificação do sujeito em face dos objetos (mercadorias culturais), à incapacidade das pessoas vivenciarem experiências enquanto atividades livres e autodirigidas. Na pura razão prática, teoria e prática são separadas numa realidade em que a teoria se torna impotente e a prática, arbitrária de uma homogeneidade padrão. Para Adorno (1992), a iniciativa no sentido de superar a padronização sem resistência, em vista da transformação social, poderá ocorrer por meio de uma pedagogia democrática, como um meio de formação e instrumento indispensável na luta pelo esclarecimento.

Ora, trazer o universo de contradições entre os discursos educacionais também auxilia na reapropriação da capacidade de autocrítica da formação pautada nos escritos dos pensadores da Teoria Crítica. A partir de uma herança que prezava a superioridade da teoria ou do saber conceitual sobre a prática é que se originou um modelo de formação defasado, excessivamente distanciado do real e que não repercutiu adequadamente no seio de sociedades complexas que vigem sob o princípio da prática. A busca pela efetiva aproximação entre as teorias e as práticas sociais deve estar presente durante a realização do que é educativo e basear-se na constatação de que na atual sociedade há um hiato muito grande entre os conteúdos das promessas de igualdade e suas respectivas realizações. Não há mais como se aquietar diante da dissimulação do processo formativo atual que, desde o início, compraz à semiformação (cultura danificada) como justificativa para a perpetuação do processo de industrialização da cultura, de submissão da teoria em relação à prática (ADORNO, 1992). O educador que faz sua autocrítica, ao se preocupar com a compreensão dos motivos que incentivam a distância entre as teorias e a práxis, trabalha com um pensamento de resistência para que o fosso entre vivências recheadas de intuições e afetos e as teorizações e modelos acadêmicos 
não sejam tão grandes, apesar da sociedade administrada funcionar com rupturas e incentivar a permanência desta distância.

De acordo com Schön (2000, p. 15), "a racionalidade técnica é uma epistemologia da prática derivada da filosofia positivista, construída nas próprias fundações da universidade moderna, dedicada à pesquisa". Essa virada prática acaba por absolutizar o próprio fazer do professor, recaindo no praticismo, uma teoria que rejeita o contexto de descoberta por esquecer que a ação já está informada por uma teoria. As condições de possibilidade do conhecimento não abolem "a íntima cumplicidade e reciprocidade entre teoria e prática no processo cognitivo" (MORAES, 2009, p. 590). Nesse sentido, Moraes adverte que as epistemologias da prática também recaem no discurso prescritivo, distante das necessidades dos contextos pedagógicos, como é exposto a seguir:

Tomando a educação como exemplo, com frequência o fascínio do modo de operar do ato educativo no cotidiano escolar transforma essa experiência em limite da inteligibilidade. Nas pesquisas e em eventos da área, são comuns uma supervalorização da subjetividade do trabalho docente e as célebres histórias ou relatos do cotidiano escolar, narrativas subjetivas e/ou descritivas, quase sempre prescritivas, eivadas de dever-ser (MORAES, 2009, p. 590).

Em contrapartida, a compreensão sobre a fragilização da teoria pode ser entendida mais especificamente no momento em que ela deixa de fazer sentido e se torna alheia à prática. Bem diferente é a própria teoria se transformar em ação, como possibilidade de equacionamento dos problemas práticos, recebendo um novo significado integralmente relacionado à ação pelo fortalecimento da instância teórica do real. Sugerimos então repensar, no campo pedagógico, a ideia do reconhecimento dialógico e social, pois uma educação inspirada nos contornos discursivos e críticos do mundo da vida oferece ganhos no sentido propedêutico, ao preparar o terreno para evitar a ocorrência de anomalias na compreensão do processo formativo. Outra dimensão seria a atividade da pesquisa que 
engloba o princípio integrador da teoria e da prática na educação capaz de estabelecer atitude dialógica com a realidade, alimentando processos emancipatórios na sociedade através do questionamento produtivo. A pesquisa na educação faz parte da noção de vida criativa e de autonomia, pois o estudante (universitário) leva para a vida o que cria por si mesmo. A relação dialética entre teoria e prática na ação pedagógica humaniza o ensinar e o aprender, desfazendo a postura reprodutiva.

Habermas (1982) afirma que todo conhecimento é posto em movimento por interesses que o orientam, pois são campos indissociáveis, assim como trabalho, interação e poder. Desse modo, ele elabora a distinção entre três tipos de conhecimentos com base nos interesses humanos que comandam o processo científico. O empírico-analítico, que tem o interesse técnico de controle, domínio da natureza; o histórico-hermenêutico, que carrega o interesse prático-comunicativo relacionado à interação dialógica dos homens entre si, e o processo dialético da ação, que corresponde ao interesse crítico emancipador, libertador do humano. Sua argumentação defende ainda que o conhecimento se dá na e pela práxis, porque a reflexão teórica se encontra energicamente apoiada na ação para transformar a realidade, trazendo também a realidade objetiva e suas relações conflitantes.

Radicalizando a análise, Habermas (1987) observa que a tendência à pedagogização da Pedagogia existe desde o século XVIII, o que transforma a educação em um sistema técnico e administrativo, regulamentado por um sistema legaliforme. Nesse entendimento, é necessário contrapor ao paradigma das ciências o corretivo da reflexão, que implica em manter vivo no discurso formativo o que havia sido pensado como mera teoria, a saber, o discurso, a comunicação, o entendimento desinibido e isento de coerção. Afinal de contas, uma ciência cuja práxis não mais se recorda da teoria, aliena o interesse que a levou a ser prática. A análise habermasiana revela a necessidade de entender o conhecimento como um jogo de interesses e interações estabelecidos no diálogo, tendo em vista que todo conhecimento é discursivo. No entanto, sabe-se que o processo 
educacional se estabelece, inicialmente, em situação de desigualdade e adequação aos imperativos funcionais, causando a opacificação da comunicação. Esta disparidade provém do maior domínio do professor em relação ao consenso preestabelecido socialmente e dos modos pelos quais ele administra as práticas de linguagem. Assim, a definição do que vem a ser o conhecimento escolar é realizado pelo professor a partir de consensos, convicções arraigadas e fundamentadas na realidade objetiva, estabilizando a reflexividade do professor no seu fazer diário.

Retomando as perspectivas de Adorno (1992), Habermas (2009) e Freire (1996), avaliamos a possibilidade de pensar a prática e a teoria na formação de professores como elementos autorreflexivos e críticos, entendidos como espaços de problematização dos saberes que, identificados na integração com as práticas cotidianas, possibilitam novas aprendizagens no mundo. A partir do estudo de Habermas, é possível identificar a possibilidade de dialogicidade e complementaridade da relação entre teoria e prática na formação de professores, considerando que os contextos de aprendizagem circulam entre ação e discurso, oferecendo a possibilidade de problematizar as práticas cotidianas e ultrapassar perspectivas individualistas, relativistas e tecnicistas. Essa abordagem permite ainda ampliar uma validação e problematização dos saberes na ação e no discurso como forma de descentramento das individualidades e certificação do sucesso na ação conjunta no mundo. Para Habermas (2009), a prática tem a função de colocar em questão os saberes e os discursos, já a teoria tem o compromisso de desproblematizar a prática. Trata-se de um movimento circular entre teoria e prática, entendido como ação e discurso, em que a aprendizagem depende da articulação entre ambas. A proposta justificada numa racionalidade comunicativa permite pensar a prática tanto como motivação para a renovação dos saberes quanto como espaço de prova das soluções discursivamente alcançadas. A incapacidade prática deve ser discutida por meio da apresentação de razões, até o alcance de acordos, pois é no confronto com a prática, que encontramos a possibilidade de crítica, aceitação ou não das expectativas 
discursivas, a partir da qual revisamos o saber tornado problemático (HABERMAS, 2009). De acordo com o autor, no discurso as pretensões conceituais são colocadas em questão à luz de razões, já na ação, à luz de decepções na experiência com o mundo. Assim, somos capazes de aprender algo mediante o relacionamento prático com uma realidade que nos resiste, facilitando o intercâmbio no agir por hipóteses para nos certificar reflexivamente acerca dos saberes.

A visão freireana (1996) de formação nos mostra que dos conceitos sempre se destaca a dupla mão, resgatando de um lado o sentido construtivo, solidário, investigativo e exorcizando de outro, o sentido autoritário dos métodos e das práticas educativas. Mas é validando os saberes no diálogo e na ação junto ao mundo, que poderemos oferecer novos horizontes à compreensão dos problemas concretos. Freire (2001) não só defende a inseparabilidade entre a dimensão teórica e prática da formação, mas adverte também que existe uma relação hierárquica entre elas, pois a competência da ação só adquire valor quando assume e expressa um determinado sentido ético-político. A posição de Paulo Freire torna-se muito oportuna neste limiar do século XXI, em que a dimensão formadora de conhecimentos tanto pode tornar-se um momento de liberdade ou de vazio, de criatividade ou de destruição. Tendo em vista que as práticas e as teorias não possuem o poder de correção de forma independente, a articulação dialógica de ambas tem um papel importante na crítica ao instituído e na problematização dos saberes como intersubjetividade reflexiva capaz de alcançar a transformação das posições. A educação é um fenômeno social, que contribui para a popularização da ciência e a difusão do conhecimento na sociedade. É um processo de aprendizagem que não acontece apenas na prática, mas circula pelas mudanças globais, pois o educador tem a tarefa de ensinar responsavelmente a ler o mundo, a ler as palavras deste mundo midiático, informando e dando o sentido humano e ético da própria formação.

Fiel à virada linguística, Habermas (2009) acredita que "na medida em que o saber se justifica por um processo de aprendizado que supera os 
velhos erros mas não nos protege dos novos, cada estado de saber atual permanece relativo à melhor situação epistêmica possível". Habermas nos autoriza a pensar que o saber problematizado tem maior chance de êxito na prática, tendo em vista que diferentes interpretações acerca do mesmo mundo são colocadas em xeque na troca argumentativa. E defende que "é apenas com a transição da ação para o discurso que os participantes adotam uma atitude reflexiva e, à luz de razões pró e contra apresentadas, disputam pela verdade tematizada de enunciados controversos" (HABERMAS, 2009, p. 49). Como já comentamos, a linguagem humana deve ser pensada como um processo vital particular e único, pelo fato de que no entendimento linguístico se torna manifesto o mundo enquanto forma de sensibilidade e comunicabilidade (GADAMER, 1999). Nesse sentido, a linguagem torna-se a base de toda e qualquer formação e construção do conhecimento, pois se reconhece que o ato formativo de construção do mundo se revela na dimensão do reconhecimento mútuo, que é inerente às ações intersubjetivamente válidas pelas quais estabelecemos relações com o mundo. A articulação entre teoria e prática na formação, constitui-se em um quadro de complexidade e indeterminação orientado pela dinâmica das forças sociais e das relações de poder. Uma alternativa plausível para os desafios da educação seria sua própria inserção vital em relação aos tipos de racionalidade, às subjetividades e suas linguagens, na medida em que confere atualidade à formação.

\section{Retomando questões}

Nesse ponto da argumentação, podemos dizer que os teóricos utilizam-se dos pressupostos da conversação para lançar pontes e transpor distâncias, acreditando na possibilidade de produzir um saber intersubjetivo, relacionado com os conceitos e com as ações cotidianas, para melhorar as práticas formativas nos processos pedagógicos. Pensar uma formação educativa para além das categorias conceituais, sobretudo nas versões metodológicas, implica numa compreensão 
do sentido que não parte semanticamente da abertura linguística ao mundo, mas pragmaticamente da busca de entendimento mútuo. A linguagem não tem morada fixa nem mesmo na escrita, porque nela há um sistema que compõe o mundo e nele interage com sua inegável força ideológica. Daí que a linguagem é uma forma de vida que se amplia e atua no diálogo enquanto práxis de compreender e fazer falar, superando as distâncias pela interação. Portanto, o intrínseco potencial estimulante da teoria e da prática podem ser tomados como força formadora (HABERMAS, 2009). O sentido da linguagem não se afasta da práxis, mas a incorpora no próprio campo de ressignificações humanas. A comunidade de diálogo não exclui nenhuma experiência de mundo, pois é o "medium universal da razão (e da desrazão) prática" (GADAMER, 2002, p. 297). O debate traz o nexo da teoria e da prática na formação pedagógica como elementos dialógicos ilimitados de nosso acesso ao mundo e de nosso aprender, oferecendo as condições de surgimento de uma racionalidade essencialmente criadora e aprendente, que se volta para um conhecimento linguisticamente mediatizado e relacionado com o agir.

A denúncia da sociedade atual revela o mundo virtual em que vivemos construído do mundo real da prática. E quanto às possibilidades de transformação desse movimento, podemos dizer que enquanto o contexto educativo reforçar a permanência da prática utilitarista e autoritária, que afasta a autorreflexão e a crítica das tecnologias, não conseguiremos vivenciar tendências transformadoras. Como podemos perceber na ação pedagógica as fronteiras entre a teoria e a práxis, assim como os mundos real e virtual tornam-se indefinidos. A prática pedagógica na construção e no uso de mundos virtuais desenvolve a capacidade para a reflexão na ação de forma sensível, como forma de despertar a humanidade das pessoas, através de uma teoria da prática interpessoal competente. Trata-se aqui de uma concepção educacional que se pauta na busca da reconciliação teórico-prática da formação (entre aqueles conteúdos emancipatórios da formação e uma vida menos injusta) e colabora para 
o estímulo da continuidade do conteúdo apreendido como processo de (auto)formação do sujeito marcado pela incerteza, singularidade e pelos conflitos de valores. Talvez se possa dizer que é necessário, por um lado, apostar em um momento de unidade entre teoria e prática, para que se possa realizar a história, mas, por outro lado, é preciso pensar essa mesma relação como separação necessária para que a contingência possa ser interlocutora da reflexão crítica, cuja mediação e confrontação decisiva acontece associada à dimensão da arte enquanto desvelamento, reconciliação e comunicação.

A atribuição de um papel virtualmente revolucionário e social à arte de educar supõe que ela possa resgatar elementos de uma forma de comunicação não corrompida pelo caráter fragmentado, uniformizador e utilitarista, mas como um agir praticado na argumentação interativa, do aprender de modo reconstrutivo, que liberta dos imperativos técnicos e interesses científicos. A virtualidade de uma cultura mais extensa e completa, que articula as dimensões teóricas e práticas da racionalidade pedagógica não pode ser vulgarizada por um conceito subordinado exclusivamente aos fins utilitários, o que resultaria numa formação mutiladora e estreita, tornando os sujeitos incapazes de considerar mais que um único aspecto da realidade com que estejam imediatamente em contato limitado. Na sociedade tecnológica e intensiva de conhecimento prático, capta-se o que é formalmente padronizável, não a semântica das ausências, das reticências, dos silêncios que exigem (re)interpretação. Tudo indica que o sujeito se reconhece no fluxo da contingência do existir natural e social, que só tem sentido na práxis cotidiana. Se todo conhecimento que busca dar conta da totalidade humana exige esforço e pesquisa, então podemos afirmar que quanto mais difícil é a atividade, mais aprendemos. Enfim, buscamos com essa iniciativa novas formas de pensar a prática educativa para criar um momento de ímpeto próprio, desenvolvendo conexões entre teoria, prática, formação e ação pedagógica, reafirmando a complexidade, incompletude e as múltiplas articulações da práxis educativa. 


\section{Referências}

ADORNO, T. W. Educação e emancipação. Rio de Janeiro: Paz e Terra, 1995.

. Anotações sobre teoria e prática. In: RAMOS-DE-OLIVEIRA, N. Quatro textos clássicos. Tradução de Newton Ramos-de-Oliveira. São Carlos: UFSCar, 1992.

BRASIL, Ministério da Educação. Conselho Nacional de Educação. Parecer CNE/CP 09, 08 de maio de 2001. Diretrizes Curriculares Nacionais para a Formação de Professores da Educação Básica, em nível superior, curso de licenciatura, de graduação plena. Brasília, 2001. Disponível em: <http://portal.mec.gov.br/cne/arquivos/pdf/009.pdf>. Acesso em: 11 Jun. 2014.

FREIRE, P. Pedagogia da autonomia. Saberes necessários à prática educativa. São Paulo: Paz e Terra, 1996.

. Pedagogia dos sonhos possíveis. Org. e apresentação de Maria Araújo Freire, São Paulo: UNESP Editora, 2001.

GADAMER, Hans-Geörg. Verdade e método I: traços fundamentais de uma hermenêutica filosófica. 3. ed. Tradução de Flávio Paulo Meurer. Petrópolis: Vozes, 1999.

. Verdade e método II: complementos e índice. Trad. Ênio Paulo Giachini. Petrópolis, RJ: Vozes, 2002.

GRAMSCI, A. Concepção dialética da história. 9. ed. Rio de Janeiro: Civilização Brasileira, 1991.

HABERMAS, J. Conhecimento e interesse. Rio de Janeiro: Zahar, 1982. (Primeira publicação em 1968).

. Teoría de la ación comunicativa, I: racionalidad de la acción y racionalización social. Madrid: Taurus, 1987. 
HABERMAS, J. Verdade e justificação - ensaios filosóficos. 2. ed. Tradução de Milton Camargo Mota. São Paulo: Edições Loyola, 2009.

MACEDO, R. S. Compreender/mediar a formação: o fundante da educação. Brasília: Líber Livro Editora, 2010.

MINASI, L. F. Formação de professores em serviço: contradições na prática pedagógica. 2008. 208 f. Tese (Doutorado em Educação) - Faculdade de Educação, Universidade Federal do Rio Grande do Sul. Porto Alegre, 2008.

MORAES, M. C. M. A teoria tem consequências: indagações sobre o conhecimento no campo da educação. Revista Educação e Sociedade, v. 30, n. 107, p. 585 - 607, Ago. 2009.

MORIN, E. Ciência com consciência. 11. ed. Rio de Janeiro: Bertrand Brasil, 2008. lina, 2007.

. O método 5: a humanidade da humanidade. Porto Alegre: SuPIMENTA, S. G. Professor reflexivo: construindo uma crítica. In: PIMENTA, S. G.; GHEDIN, E. (Org.). Professor reflexivo no Brasil: gênese e crítica de um conceito. 4 ed. São Paulo: Cortez, 2006.

SCHÖN, D. A. Educando o profissional reflexivo: um novo design para o ensino e a aprendizagem. Trad. Roberto C. Costa. Porto Alegre: Artes Médicas Sul, 2000.

TARDIF, M. Saberes docentes \& formação profissional. 11. ed. Petrópolis: Vozes, 2010.

Data de registro: $11 / 08 / 2014$

Data de aceite: 01/08/2015 